\title{
USING DATA ON BIKE-SHARING SYSTEM USER STOPOVERS IN SMART TOURISM: A CASE STUDY
}

\author{
Krystian Banet \\ Department of Transportation Systems, Cracow University of Technology, Cracow, Poland \\ *E-mail of corresponding author: kbanet@pk.edu.pl
}

\begin{abstract}
Resume
Bike-sharing systems are an important element in development of the smart cities and datasets from these systems are one of the ways to obtain large amount of information on bicycle traffic. These usually contain data on the origin and destination of each trip, as well as its time and duration. Alongside the basic data, some operators also provide information on the exact route picked by each user. This allows researchers to study stopovers, which may serve as a source of interesting information on human behaviour in public spaces and, as a consequence, help improve its analysis and design. However, using the raw data may lead to important errors because most stops occur in the vicinity of bike stations or are related to traffic problems, as evidenced by the case study of Cracow. The data filtering method proposed below opens up the possibility for using such datasets for further research on bike user behaviour and public spaces.
\end{abstract}

Available online: https://doi.org/10.26552/com.C.2021.2.G1-G12

\section{Article info}

Received 2 September 2020

Accepted 11 October 2020

Online 9 March 2021

\section{Keywords:}

bicycle traffic, bike-sharing, transport geography, stopover behaviours

\section{Introduction}

The advent of the bicycle forever changed the way we travel and increased our freedom. The growth of bike traffic was only halted by the rise of the automotive industry; however, because of their many advantages, bicycles are once again becoming popular as means for the daily commute. The vision of "smart cities" rests on the central idea that investment in social capital, technology and infrastructure should fuel the growth of the city and continually improve the quality of life for its residents. One of the pillars of the "smart" philosophy is to provide modern and integrated transportation, the pivotal element of which is development of the bike-sharing systems, which have been growing in importance in recent years, not only in the largest metropole, but in the medium-sized towns and even the smallest municipalities, as well [1]. Better understanding of users of the bike-sharing systems can help in smart tourist management in urban areas. Cities around the world are increasingly recognizing the smart tourism city concept and related strategies as means of optimizing sustainable environments. Particularly for cities facing emerging issues of residents' negative perceptions towards tourism, smart tourism city empowers a city to rise to this challenge by creating urban spaces that residents and visitors can enjoy together [2].

Apart from becoming a convenient means of the lastmile transportation, city bikes have become a valuable source of information on trips taken by hundreds of thousands of cyclists, a data pool impossible to collect with use of classical traffic measurement methods. Thanks to bike-sharing datasets, it is now possible to perform a more accurate modelling of the bicycle traffic and examine the individual elements that shape the demand for such services. Over the last few years, a number of studies have already focused on analysing the factors that affect the traffic within the framework of city bike systems. These surveys usually aim to identify potential locations for new stations, estimate traffic flows and bike use, and include social and demographic variables, as well as data on spatial organization.

In contrast, this article focuses on analysing datasets from a single city bike system to look at the issue of stopovers; no previous study of this kind was identified in the literature review process. The bike-sharing systems are an interesting source of data on human behaviour in public spaces, which can be useful for spatial analysis and design, including in terms of developing bike infrastructure. Analysis in question is focused on a case study of Cracow. Once the dataset obtained from the city bike system was cleansed, user stopovers were visualized to create a map of local-related stop concentrations, which largely overlapped with rental stations. Analysing data in this form would be ineffective; a method of filtering data on city bike user stopovers had to be developed, which is the main objective of this article, to help understand the bike-sharing system stopovers behaviour and obtain more precious data to delimit attractive public spaces in the city. The visualization of the final data sample demonstrated the effectiveness of the method and enabled further analysis, which may prove 
useful for urban planners and sociologists, allowing them to better understand cyclists' behaviour and user preferences regarding areas in which their stopovers occur.

The paper is organised as follows. In the next section, the background to city bike systems, the data collected and their usage are introduced. In section 3 , a generic method is introduced to identify and filter the stopovers in mobility traces and apply it to the city bike data. In section 4 , the method is illustrated using the example of Cracow. Finally, in section 5, the results are synthesized and the potential applications and limitations of the proposed method are discussed.

\section{Literature review}

With acceleration of urbanization, a number of cities face challenges to design and develop a better city for living [2]. The concept of the smart city is to optimize infrastructures in order to ideally ensure quality of citizens' life: transportation, water and power supply, waste management, IT connectivity, efficient urban mobility, e-governance and citizen participation, [3]. Cycling has strategic importance for the sustainable development of cities and has become one of the fundamental parts of the urban mobility strategies. Use of bikes as a transportation solution in urban and/or tourist contexts is universally recognized as positive due to the lack of polluting emissions, the reduction of traffic congestion and improvement of users' health [4]. Transportation with accommodation, gastronomy, attraction and ancillary service is one of the essential components of the smart tourism [2]. There are six main tourist-related elements of the smart cities: smart mobility, smart government, smart economy, smart people, smart living and smart environment [5]. Presence of an effective bike sharing service, being part of a smart mobility, can indeed make a city more attractive and easier to visit, strongly motivating tourists to choose it as a holiday destination. Bike trips can also become an integral part of the tourist experience, even when implemented to connect specific points of interest to the city center [4].

The growth in bike traffic has attracted the attention of researchers and spawned multiple studies of its various aspects. The bicycle traffic has long been appreciated for its health benefits. However, it has important advantages not only for health and physical fitness, but also for the natural environment. Choosing the bike as a means of transportation may be dictated by various individual and environmental factors, including age and gender [6]. Because of its seasonal nature, randomness of choice and dependence on weather conditions, however, bike traffic is far from easy to forecast and model. Reliable studies on the subject are also difficult to carry out. The most extensive data on pedestrian and bicycle traffic usually come from Complex Traffic Studies, conducted on a local and regional level in individual households. However, the most popular way to collect bike traffic data continues to consist of counting cyclists in the field, despite its rather limited value for understanding the human transport behaviour [7]. Until not so long ago, exact figures on bike demand were extremely difficult to come by because of insufficient data; today, however, we observe a rapid rise in availability of relevant statistics. The new, exhaustive datasets that have come to complement classical methods rely on automated meters or publicly available GPS traces [8]. One way to obtain large quantities of data on bike traffic today is to analyse records from the short-term bike-sharing systems [9]. This data source meets the definition criteria for big datasets and has enormous potential for study of urban dynamics and aggregate human behaviour [10]. Recently, bicycle sharing has been becoming increasingly popular around the world. As a potential travel mode for both the "first mile" and "last mile" transportation solutions, bicycle sharing is usually used at the beginning or end of the trip chain and play an important role in bridging the gap among existing transportation networks and is useful for recreation and tourism-related activities [11].

The Global Positioning System (GPS) has been gaining importance for travel surveys since the 1990s. While it is successfully used to collect accurate information about travelled routes and travel times, only little is known on extracting added information like transport modes and trip purposes [12]. City bike systems store multiple records of trips by thousands of cyclists, who, by using the service, consent to the collection of their GPS traces, along with data on each individual trip. This allows improvements to accuracy of the bike traffic modelling, as well as in studying the factors that shape the demand for the city bike system services.

Compared to other public travel modes, the bicycle sharing travel data usually include the starting or ending point of the original trip chains, which is more useful for the land-use analysis [11]. Over the last few years, a number of studies have been devoted to analysing the factors that affect traffic within the framework of city bike systems. These surveys are usually aimed at identifying potential locations for new stations and estimating traffic flows and bike use and include social and demographic variables, data on spatial organization (such as population and job density), as well as topological and meteorological parameters for all the proposed spots [13-15]. Data from the city bike systems have also been used to study the systems already in place [16], e.g. in Turin, Italy to estimation of passenger transport flows for development of the transport models in urban contexts [17]. Such studies look at how, for instance, bike trips are affected by factors such as: the number of retail stores and business offices near bike stations, various demographic features, job density, type of buildings and spatial organization, purpose of buildings in the area, impact of meteorological factors, the closest bike infrastructure, or the type of available transport solutions [13, 18-26]. The spatio-temporal usage patterns of dockless bike-sharing service, linking to metro stations, have been analysed e.g. in Shanghai, China [27]. Using the data from the bike-sharing in Beijing, China, Wang et. al. applied the geographic weighted regression model to 
carry out a spatiotemporal characteristic analysis of the relationship between the bike-sharing usage in railwaystation service areas and its determinants, including the passenger flow in stations, land use, bus lines and roadnetwork characteristics [28]. However, the literature review has not identified any in-depth analyses of city bike user stopovers to identify and delimit attractive public spaces. Identified attractive spaces were usually based on arbitrary expert knowledge. Other traditional methods include data from accommodation providers and guest surveys, which are time consuming and expensive. Data can also be taken from official guides, but these fail to adapt to the rapidly-changing tastes of tourists and their actual preferences [29]. Today, everyone leaves digital footprints on the internet, which can be used as data what is essential of smart tourism. The literature contains works that aimed to identify tourist hotspots based on user activity on recommendation websites and social media such as Flickr or Twitter [29-31]. The similar idea is followed in this paper and explore how the bike-sharing system data may help in revealing spatial patterns of touristic cities. Mobility traces from public bikes, were broadly employed in transport and spatial analyses, yet, so far, have not been used to identify tourist hotspots [32].

\section{$3 \quad$ Methodology}

This article presents a data filtering method, which allows the dataset to be trimmed down to guarantee that it only includes user stopovers that were not related to traffic problems or technical activities involved in locking and unlocking the bike at the rental station or checking its technical condition before the trip. Dataset obtained after filtering process can be used for further analysis of attractive public spaces.

The dataset first needs to be cleansed in order to discard data, like for instance records where location tracking failed or the bike was rented only to be returned moments later due to, e.g. a technical glitch. The datasets from the GPS transmitters are stored in GPX-files (GPX is an XML schema designed as a common GPS data format). To read the data in these GPX files, a Python code was developed that presents it as a set of trip parameters: the trip identification number, the number of segments, trip duration, idle times, total distance and mean velocity. Accordingly, the dataset obtained from the city bike system was first cleansed of corrupt records related to signal failures in the GPS transmitters. The trip data were eliminated if the GPS outage lasted at least five minutes. After the first filtering stage, the sample continued to contain many trips with an average speed of $0 \mathrm{~km} / \mathrm{h}$. Therefore, it is also decided to eliminate all the trips with a duration or distance of 0 , most likely related to situations where a bike was unlocked, but not taken out of the stand, and then locked again, e.g. because of a technical problem. At the last stage, the records that contained information on very short trips, which could correspond to situations where a technical problem was discovered soon after the bike was rented or the user decided not to continue with the trip, were removed, [33]. The final sample was subsequently studied to analyse the remaining stopovers. The stopover is a set of consequent travel segments characterized by zero value of covered distance:

Stopover $=T S_{\text {idle }}\left\{T S_{k}, T S_{l}: l=k+1\right\}, k, l=1 \ldots N_{T S}$,

where $T S_{\text {idle }}$ is a set of all the segments within the trip that have zero travel distance; $T S_{k}$ is the $k$-th trip segment of the journey track; $N_{T S}$ is the total number of trip segments.

The first step was to identify locations where users started their trips, which did not always overlap with the bike rental stations, since, in Cracow, the operator allowed users to leave the bike anywhere within the city for an extra charge. The corresponding heatmap, however, shows that almost all the trips began at bike stations. First, the number of stops within a radius of 1 to $20 \mathrm{~m}$ from the trip origin was studied and it was looked at percentage drops in the number of stopovers in the vicinity of the origin site to identify the point of stability, beyond which the number could be described by a linear function with the coefficient of determination $\mathrm{R}^{2}$ equal to $99 \%$. The data thus filtered then underwent another round of filtering.

The second stage served to eliminate stops related to traffic problems. In order to include stopovers by cyclists who used bicycle lanes and sidewalks, as well as those cycling on public roads, it was decided to focus on areas around pedestrian crossings and traffic lights. This stage relied on vector data from the Open Street Map, which included information on their geographical coordinates. The analysis focused on stopovers that occurred within a radius of 5 to 50 meters from a pedestrian crossing. Once again, percentage drops were studied to identify the point of stability, but manual corrections had to be introduced at this stage. A number of control points were examined at which long waiting lines of bicycles were identified at pedestrian crossings and adjusted the radius accordingly so as to discard data from such spots. The same approach was adopted at the third stage regarding the railway crossings.

The last step focused on stopover duration. It was decided to discard very short stops, which could be related e.g. to temporary stopovers at the intersections of uncontrolled neighbourhood roads that did not have a pedestrian crossing (and which, for this reason, had not been eliminated at the second filtering stage). A fixed time threshold was calibrated at several known locations where cyclists typically stopped and then adjusted to effectively filter out the traffic-related stopovers. The data sample obtained after the last filtering stage were also visualized as a heatmap.

In addition, after every stage of filtering factor of filtering effectiveness was checked. It is described by formula:

$F_{i}=\frac{x_{F}}{x_{i}}, i=0 \ldots 4$, 
Table 1 Weather conditions measured at the Cracow-Balice station (developed based on [34])

\begin{tabular}{|c|c|c|c|c|}
\hline day & mean temperature $\left[{ }^{0} \mathrm{C}\right]$ & $\max$ temperature $\left[{ }^{0} \mathrm{C}\right]$ & total rainfall $[\mathrm{mm}]$ & $\begin{array}{c}\text { mean pressure } \\
{[\mathrm{hPa}]}\end{array}$ \\
\hline 31 May 2017 & 19.5 & 24.5 & 0.1 & 1016.0 \\
\hline 1 June 2017 & 17.1 & 22.2 & 0.0 & 1019.0 \\
\hline 2 June 2017 & 16.7 & 24.4 & 0.0 & 1018.1 \\
\hline 3 June 2017 & 17.3 & 24.4 & 0.0 & 1016.6 \\
\hline 4 June 2017 & 19.6 & 28.9 & 3.6 & 1010.8 \\
\hline 5 June 2017 & 18.0 & 22.7 & 0.0 & 1015.3 \\
\hline 6 June 2017 & 21.3 & 28.4 & 0.0 & 1008.1 \\
\hline 7 June 2017 & 16.9 & 26.0 & 0.0 & 1014.2 \\
\hline
\end{tabular}

Table 2 The number of stopovers near the trip origin

\begin{tabular}{|c|c|c|c|}
\hline radius $\mathrm{r}[\mathrm{m}]$ & $\begin{array}{l}\text { stopovers within a radius } \mathrm{r} \\
\text { from the trip origin }\end{array}$ & other stopovers & difference [\%] \\
\hline 1 & 38375 & 15768 & - \\
\hline 2 & 42541 & 11602 & -0.26421 \\
\hline 3 & 43487 & 10656 & -0.08154 \\
\hline 4 & 43865 & 10278 & -0.03547 \\
\hline 5 & 44110 & 10033 & -0.02384 \\
\hline 6 & 44321 & 9822 & -0.02103 \\
\hline 7 & 44504 & 9639 & -0.01863 \\
\hline 8 & 44684 & 9459 & -0.01867 \\
\hline 9 & 44834 & 9309 & -0.01586 \\
\hline 10 & 44972 & 9171 & -0.01482 \\
\hline 11 & 45109 & 9034 & -0.01494 \\
\hline 12 & 45233 & 8910 & -0.01373 \\
\hline 13 & 45358 & 8785 & -0.01403 \\
\hline 14 & 45455 & 8688 & -0.01104 \\
\hline 15 & 45550 & 8593 & -0.01093 \\
\hline 16 & 45652 & 8491 & -0.01187 \\
\hline 17 & 45748 & 8395 & -0.01131 \\
\hline 18 & 45828 & 8315 & -0.00953 \\
\hline 19 & 45922 & 8221 & -0.0113 \\
\hline 20 & 46007 & 8136 & -0.01034 \\
\hline
\end{tabular}

where $x_{i}$ is a number of all the stopovers after the $i$-th stage of the filtering procedure; $x_{i}$ is the total number of stopovers obtained after the final stage of filtering. Factor $\mathrm{F}$ allows the numerical assessment of results obtained at the corresponding stage of filtering. To sum up, the adopted methodology of data filtering allows for obtaining information about stops of the city bike users from the raw data set, which:

- were not related to renting a bike at a station and checking its technical condition,

- were not stops related to the road traffic obstructions, e.g. in vicinity of pedestrian crossings, railway crossings and traffic lights,

- twere not short stops related to the difficulties in general traffic.

\section{Case study: stopovers in the bike-sharing system of Cracow}

The filtering method was tested using the example of Cracow, in a case study based on datasets obtained from the local bike-sharing system, the first of this kind in Poland. Known as "Wavelo", the system was established in 2008 and, in different guises, continued in place until 2019. The records in question covered one week of the high tourist season in 2017, i.e. the period between 31 May and 7 June. According to data provided by the Institute of Meteorology and Water Management, weather conditions at the time were auspicious for bike traffic and recreation (Table 1). The sample represented the total population of city bike users in Cracow over the analysed period and 


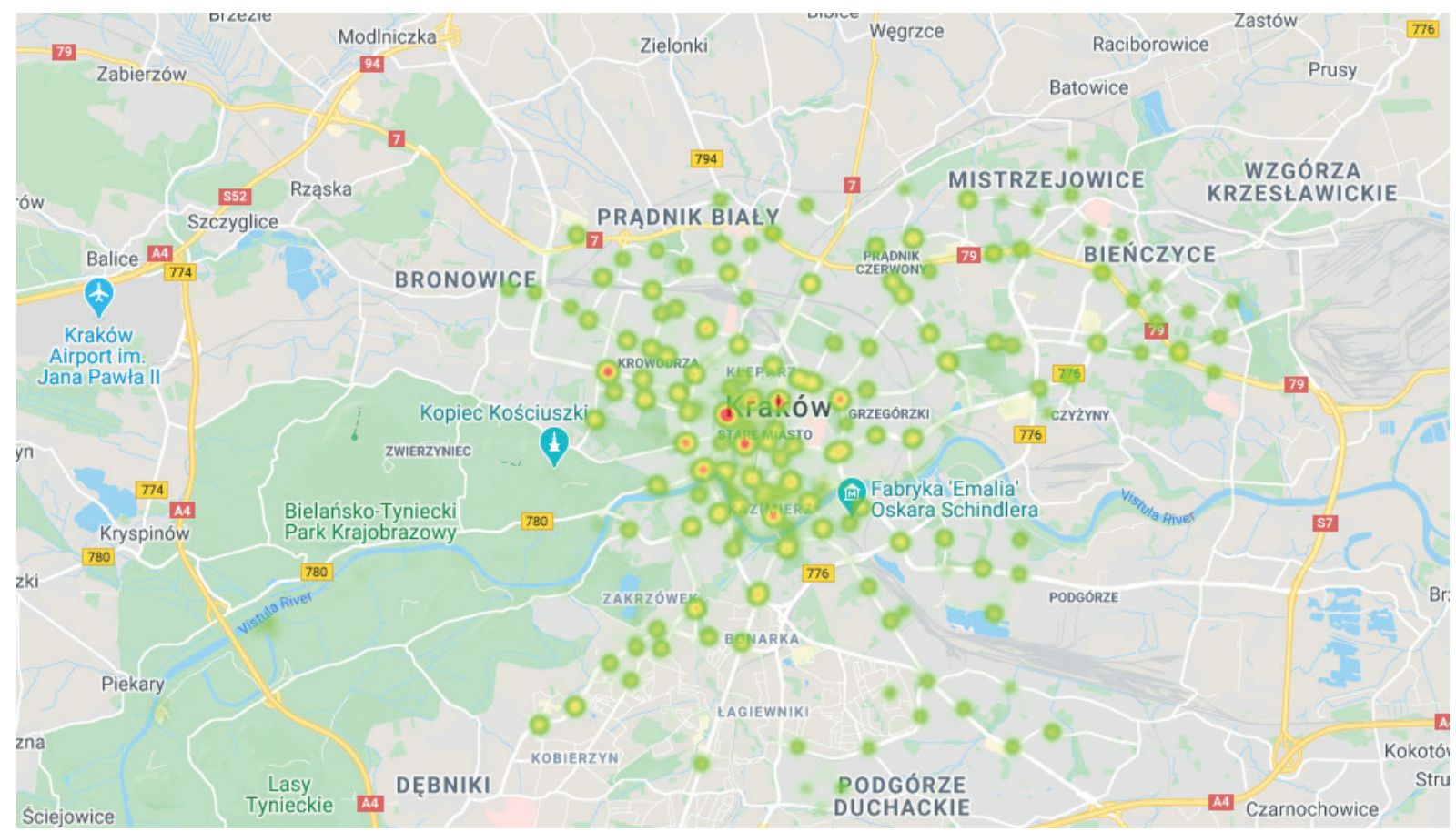

Figure 1 A heatmap showing the stopover locations of the city bike users in Cracow - cleansed sample before filtering (background: Google Maps)

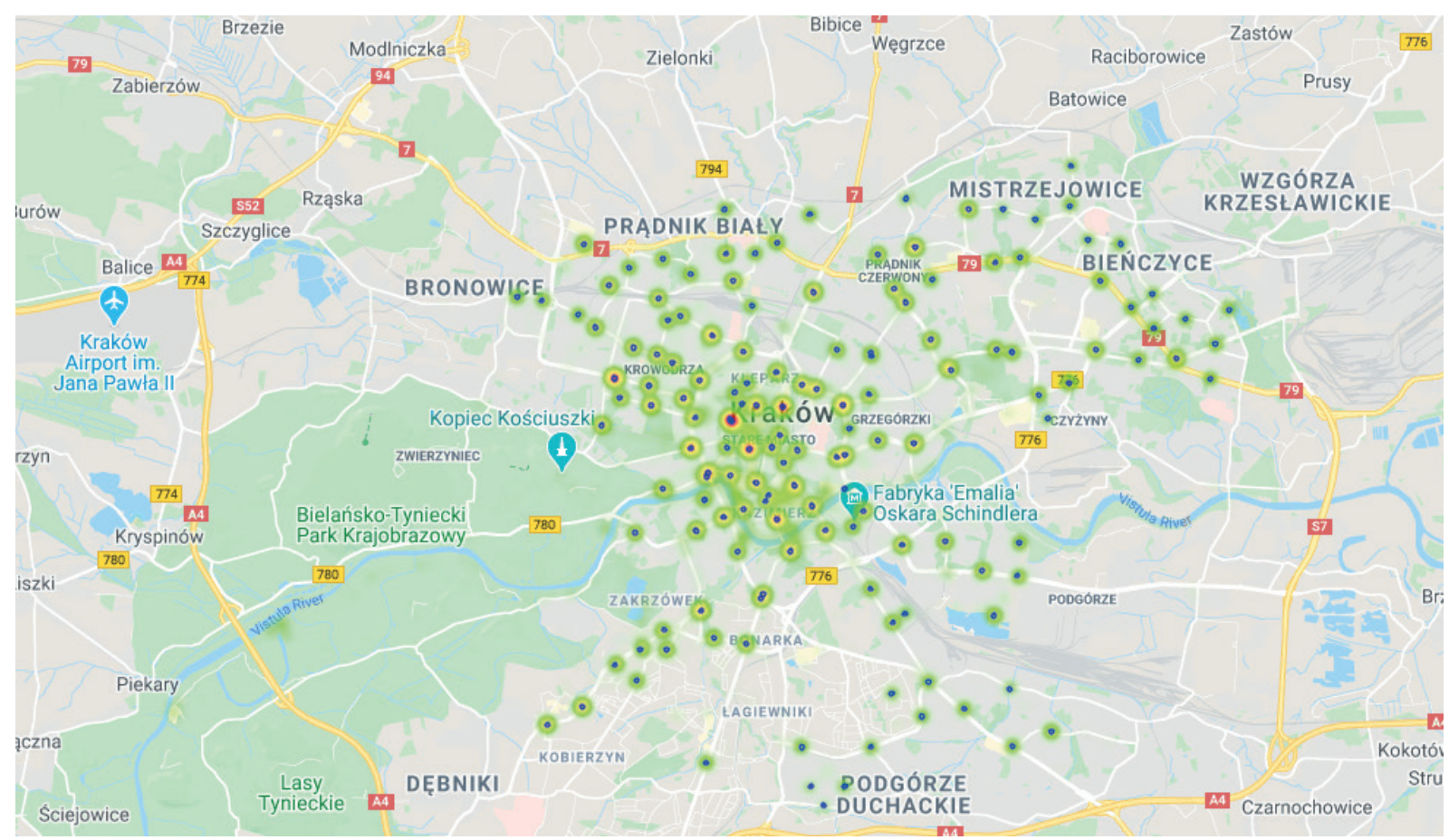

Figure 2 A heatmap showing the origin and destination of trips by the city bike users in Cracow with information about locations of the public bike rental stations (background: Google Maps)

was judged sufficient for analysis, containing a total of 34,969 tracks. The data on routes was obtained from the GPS transmitters attached to every Wavelo bike; apart from the origin and destination of each trip, the devices also recorded its itinerary. The data on each trip were presented as a list of points, with specific locations (geographical latitude and longitude) and readout times.

The first step was to cleanse the dataset provided by the city bike system. First, all the data corrupted by the
GPS transmission failures (a total of 5,946 trips) were eliminated. At the second stage, 40 trips with a duration of zero and 635 trips with a distance of zero were discarded. The third stage, which involved filtering out short trips, identified 421 trips with a distance shorter than $50 \mathrm{~m}$. Once these were eliminated, the final sample consisted of 27,927 routes.

The number of stopovers in the cleansed sample was 54,143 , with a mean duration of 79.17 seconds. A heatmap 


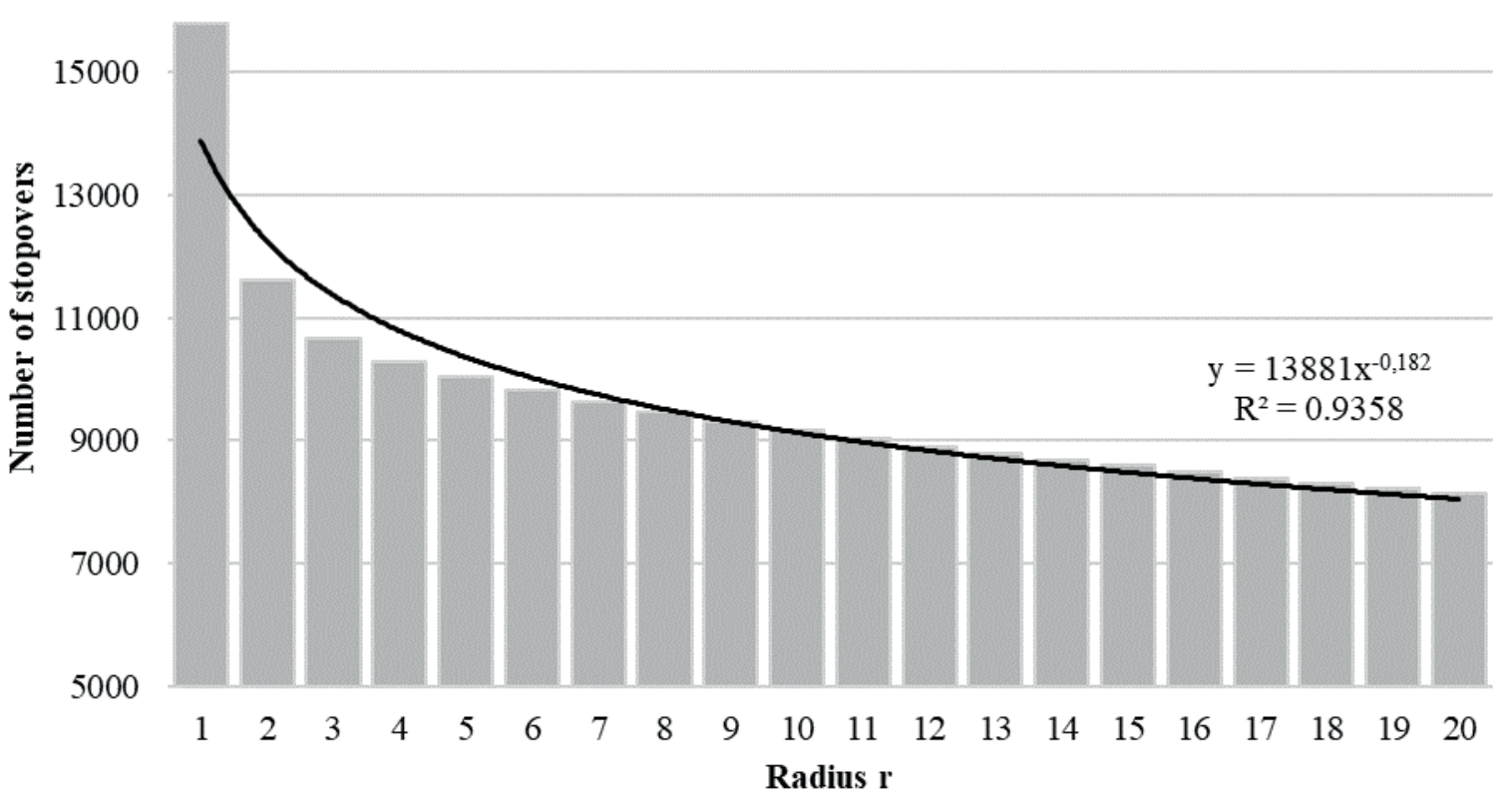

Figure 3 The number of stops at a radius greater than $r$ from the trip origin

Table 3 The number of stopovers near the pedestrian crossings

\begin{tabular}{cccc}
\hline radius r $[\mathrm{m}]$ & $\begin{array}{c}\text { stopovers within radius } \mathrm{r} \text { from } \\
\text { the crossing }\end{array}$ & other stopovers & difference [\%] \\
\hline 5 & 312 & 9327 & - \\
10 & 1301 & 8338 & -0.10604 \\
15 & 2055 & 7584 & -0.09043 \\
20 & 2551 & 7088 & -0.0654 \\
25 & 2976 & 6663 & -0.05996 \\
30 & 3362 & 6277 & -0.05793 \\
35 & 3717 & 5922 & -0.05656 \\
40 & 4072 & 5567 & -0.05995 \\
45 & 4389 & 5250 & -0.05694 \\
50 & 4695 & 4944 & -0.05829 \\
\hline
\end{tabular}

in Figure 1 shows the stopovers included in the cleansed dataset before filtering.

The map indicates that most stopovers concentrated around the city bike stations, i.e. the origin and destination of each trip, which are shown in Figure 2.

In accordance with the adopted methodology, the first filtering stage discarded all stopovers in the vicinity of the trip origin. The stopovers within a radius of $20 \mathrm{~m}$, spaced at intervals of $1 \mathrm{~m}$ were considered (Table 2).

As evidenced by the table, the drop in the number of stopovers beyond radius $r$ stabilizes at a distance of 7 meters. The number of stops beyond the radius of 1 to $20 \mathrm{~m}$ can be described by a linear function with $\mathrm{R}^{2} \approx 0.94$; beyond the radius of 7 to $20 \mathrm{~m}$, the coefficient is even higher and equals: $\mathrm{R}^{2} \approx 0.99$. A histogram showing the number of stops beyond radius $\mathrm{r}$ (from 1 to $20 \mathrm{~m}$ ) is presented in Figure 3 .
After the first filtering stage, the sample included all the stopovers that occurred at a distance of more than $7 \mathrm{~m}$ from the trip origin. The second step studied stops in the vicinity of pedestrian crossings, analysing those within a radius of $50 \mathrm{~m}$, spaced at $5 \mathrm{~m}$ intervals (Table 3 ).

The table indicates that the drop in number of stopovers beyond radius $\mathrm{r}$ stabilized at $15 \mathrm{~m}$. The number of stops beyond the radius of 5 to $50 \mathrm{~m}$ could be described by a linear function with $R^{2} \approx 0.96$; beyond the radius of 15 to $50 \mathrm{~m}$, however, the coefficient was even higher and equalled $\mathrm{R}^{2} \approx 0.99$. A histogram showing the number of stops beyond radius $\mathrm{r}$ (from 5 to $50 \mathrm{~m}$ ) is presented in Figure 4.

However, an analysis performed at selected control points, i.e. pedestrian crossings situated along main bike traffic corridors, showed that the $15 \mathrm{~m}$ radius was not sufficient to eliminate all the stops related to the presence 


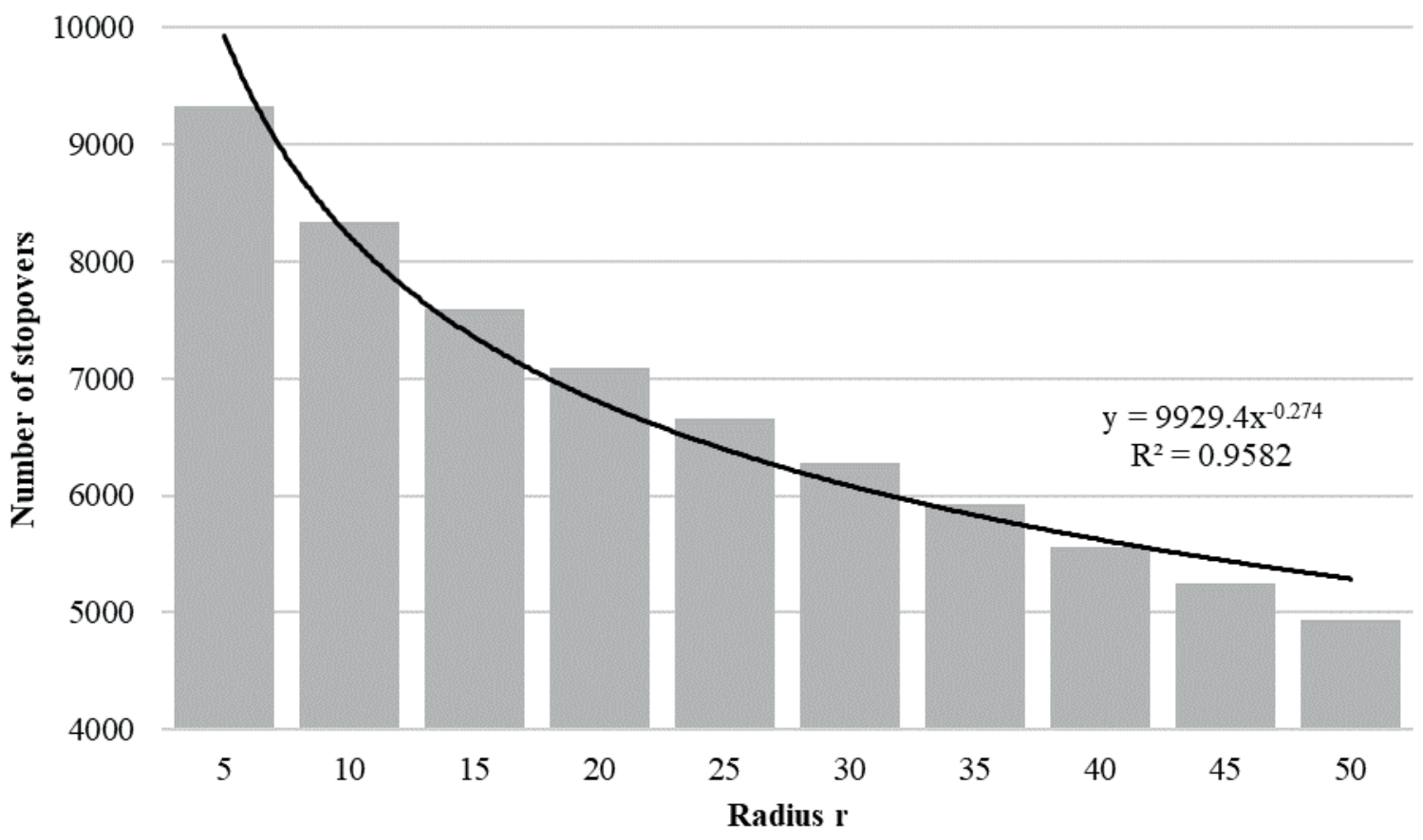

Figure 4 The number of stops within a radius greater than $r$ from the pedestrian crossing

Table 4 Stopovers in the vicinity of the railway crossings

\begin{tabular}{cccc}
\hline radius r $[\mathrm{m}]$ & $\begin{array}{c}\text { stopovers within radius r from } \\
\text { the crossing }\end{array}$ & other stopovers & difference [\%] \\
\hline 5 & 0 & 6277 & - \\
10 & 8 & 6269 & -0.00127 \\
15 & 20 & 6257 & -0.00191 \\
20 & 41 & 6236 & -0.00336 \\
25 & 52 & 6225 & -0.00176 \\
30 & 58 & 6219 & -0.00096 \\
35 & 61 & 6216 & -0.00048 \\
40 & 61 & 6216 & 0 \\
45 & 61 & 6216 & 0 \\
50 & 63 & 6214 & -0.00032 \\
\hline
\end{tabular}

of pedestrian crossings, since cyclists tended to cluster in long lines at such spots. To discard all such data, a 30-m cut-off radius had to be adopted for the purposes of the study. After the second filtering stage, the sample thus included all the stopovers that occurred at a distance of more than $7 \mathrm{~m}$ from the trip origin and $30 \mathrm{~m}$ from pedestrian crossings. The third step was to discard all the data from the vicinity of railway crossings. To do so, the stopovers that occurred within a radius of $50 \mathrm{~m}$, spaced at $5 \mathrm{~m}$ intervals, were studied (Table 4).

In this case, the number of stopovers beyond radius r remained nearly constant at distances of $30,35,40,45$ and $50 \mathrm{~m}$, which means it was easy to determine the upper distance limit. This cut-off radius was also confirmed at control points, i.e. cyclists tended to cluster in lines of max. $30 \mathrm{~m}$. A histogram showing the number of stopovers beyond radius $\mathrm{r}$ is presented in Figure 5.

After the third filtering stage, the sample thus contained stopovers that occurred at a distance of more than $7 \mathrm{~m}$ from the trip origin, $30 \mathrm{~m}$ from a pedestrian crossing and $30 \mathrm{~m}$ from a railway crossing. An analysis performed at control points, however, revealed that the data still included some traffic-related stops, e.g. those on uncontrolled neighbourhood roads without a pedestrian crossing (which had not been eliminated at the previous filtering stages). The fourth stage thus focused on stopover duration. The span of 30 seconds was confirmed at selected control points as a reliable cut-off point for stopovers unrelated to traffic. A table was then drawn up to illustrate the number of stopovers and their duration (Table 5).

A histogram showing stopovers longer than the minimum duration $\mathrm{T}$ is presented in Figure 6 . 


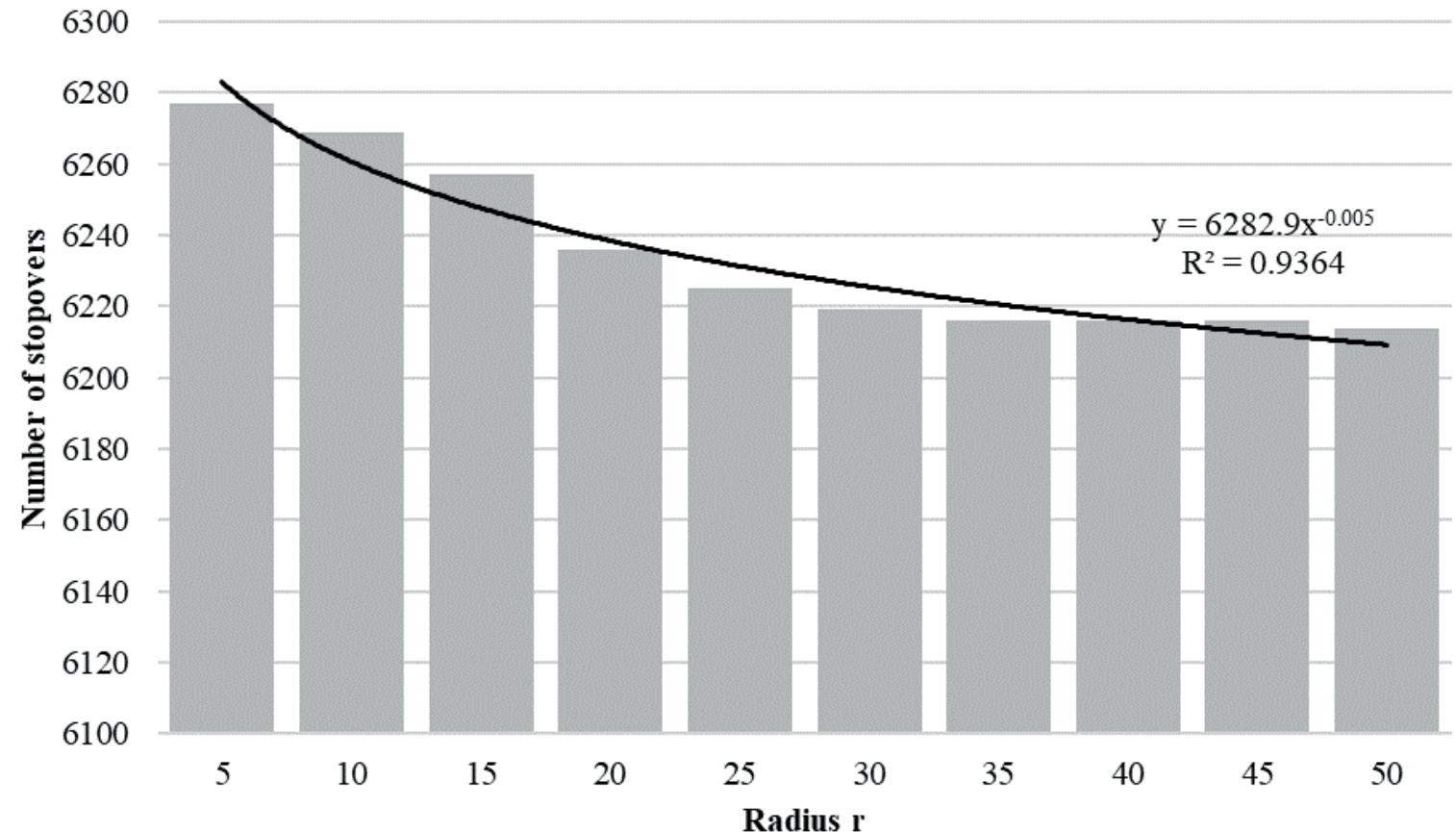

Figure 5 The number of stops within a radius greater than $r$ from the railway crossing

Table 5 Stopovers and their minimum duration

\begin{tabular}{cccc}
\hline $\begin{array}{c}\text { minimum stopover duration } \\
\mathrm{T}[\mathrm{s}]\end{array}$ & stopovers shorter than $\mathrm{T}$ & other stopovers & difference [\%] \\
\hline 5 & 116 & 6103 & - \\
10 & 257 & 5962 & -0.0231 \\
15 & 320 & 5899 & -0.01057 \\
20 & 368 & 5851 & -0.00814 \\
25 & 411 & 5808 & -0.00735 \\
30 & 428 & 5791 & -0.00293 \\
35 & 443 & 5776 & -0.00259 \\
40 & 452 & 5767 & -0.00156 \\
45 & 461 & 5758 & -0.00156 \\
50 & 469 & 5750 & -0.00139 \\
55 & 471 & 5748 & -0.00035 \\
\hline
\end{tabular}

Table 6 Stopover statistics at each filtering stage

\begin{tabular}{cccccccccc}
\hline \multirow{2}{*}{ stage } & $\begin{array}{c}\text { number of } \\
\text { stops }\end{array}$ & mean & std & min & $25 \%$ & $50 \%$ & $75 \%$ & $\max$ & sum $[\mathrm{h}]$ \\
\hline $\begin{array}{c}\text { before } \\
\text { filtering }\end{array}$ & 54143 & 79.17 & 291.63 & 1 & 15 & 25 & 65 & 27350 & 1190.77 \\
$1^{\text {st }}$ & 9639 & 280.93 & 559.30 & 1 & 85 & 90 & 255 & 8290 & 752.2 \\
$2^{\text {nd }}$ & 6277 & 335.83 & 647.13 & 1 & 85 & 155 & 275 & 8290 & 585.56 \\
$3^{\text {rd }}$ & 6219 & 337.74 & 649.78 & 1 & 85 & 160 & 275 & 8290 & 583.45 \\
$4^{\text {th }}$ & 5791 & 361.80 & 667.09 & 31 & 85 & 170 & 335 & 8290 & 582.00 \\
\hline
\end{tabular}

The fourth stage was the last in the filtering process. The final sample contained all the stopovers that occurred at a distance of more than $7 \mathrm{~m}$ from the trip origin, $30 \mathrm{~m}$ from a pedestrian crossing, $30 \mathrm{~m}$ from a railway crossing and lasted more than 30 seconds. The number of stopovers in the filtered sample was 5,791, with a mean duration of 
6200

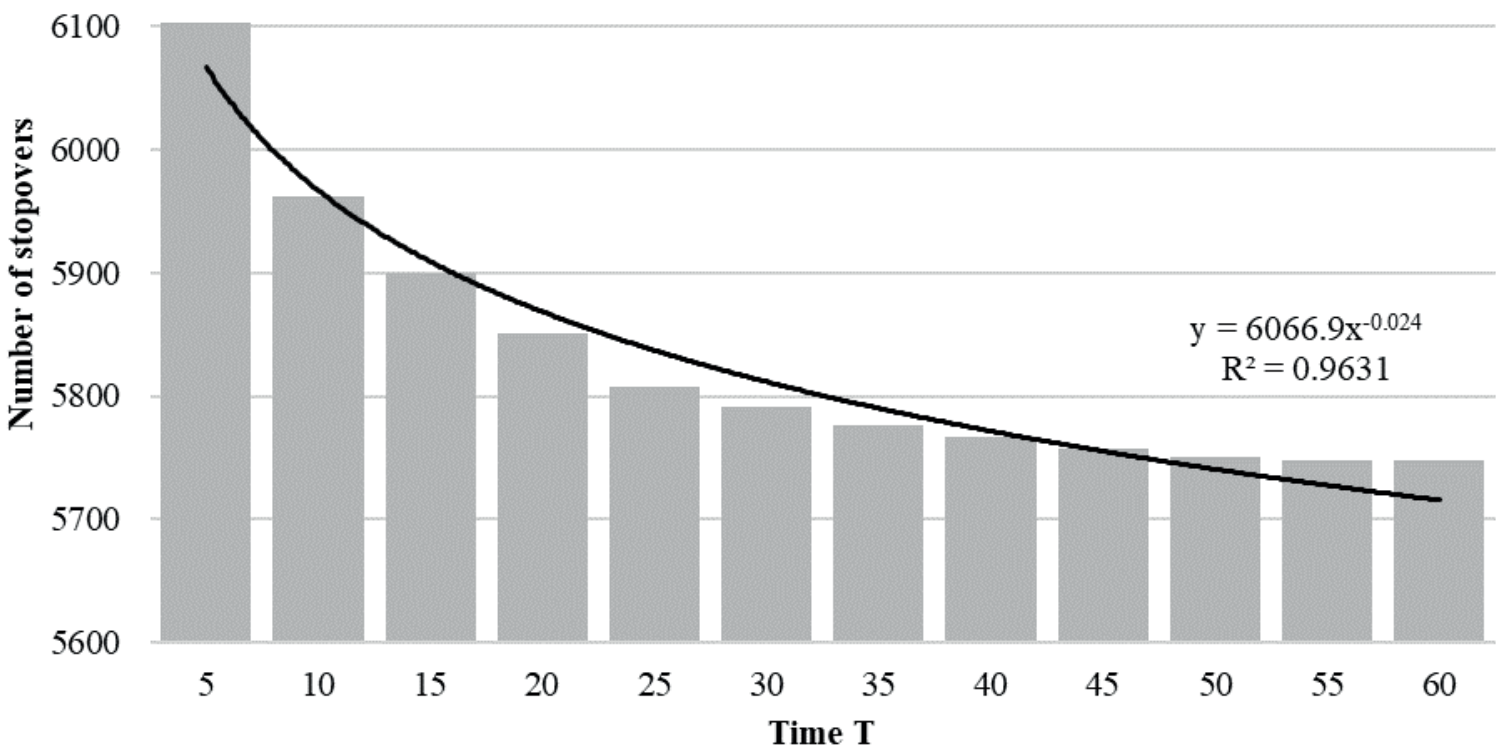

Figure 6 The number of stopovers longer than the minimum duration $T$

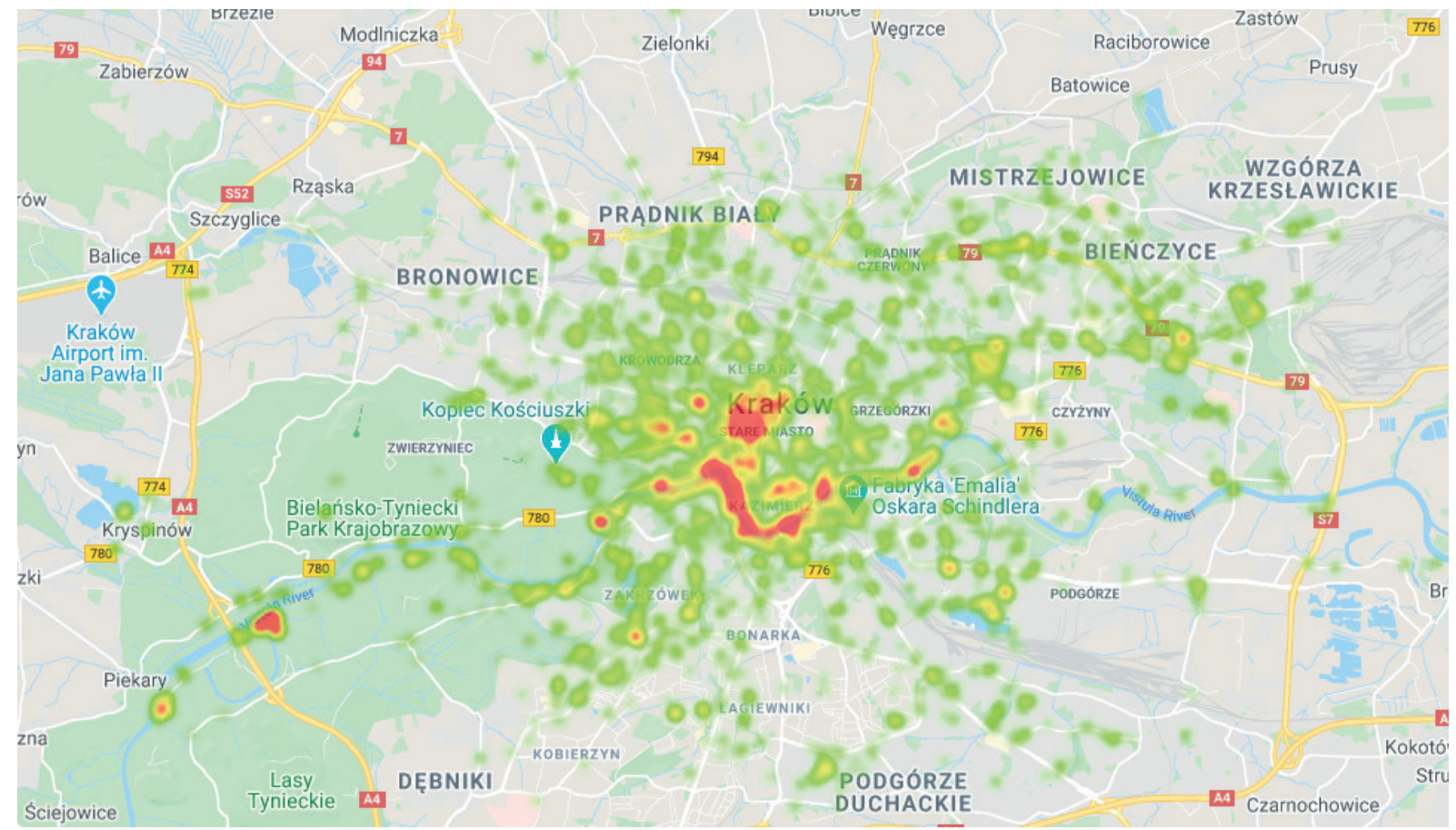

Figure 7 A heatmap showing the stopover locations of the city bike users in Cracow - a cleansed and filtered sample (background: Google Maps)

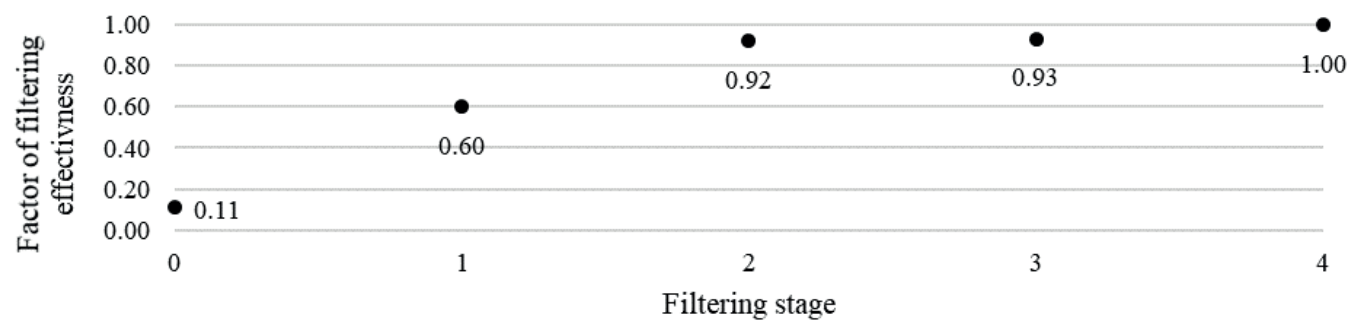

Figure 8 Factor of filtering effectiveness after each stage of filtering 
a little over 6 minutes; only $25 \%$ of all the stops, however, were longer than 5 minutes 35 seconds. Table 6 shows the basic sample statistics obtained after each filtering stage. The largest drop in the number of stopovers was recorded after the first step, which involved eliminating all those within a radius of $7 \mathrm{~m}$ from the trip origin. Further decreases were less steep, but a clear relationship could still be observed between an increase in the mean duration and the lower number of stopovers in the sample.

The stopovers that remained after the filtering process were visualized in the form of a heatmap shown in Figure 7.

Analysis of the obtained data shows that the concentration of the city bike users stopovers takes place in areas indicated by guidebooks as the most attractive in Cracow, i.e. in the Old Town area - around the Main Market Square, Old Jewish District Kazimierz and the Vistula Boulevards. A visual analysis of the heatmap shows that the areas of Blonia Common Green, the canoeing track and the monastery in Tyniec are also attractive for bike-sharing system users.

At the end of each filtering stage the filtering effectiveness factor $\mathrm{F}$ was checked (Figure 8). It shows that only $11 \%$ of stopovers in raw sample were not connected with the rental stations or traffic. The most visible difference is observed after the first stage - $60 \%$ of stopovers were connected with recreation or services (not with rental or traffic). After the second stage it was $92 \%$ and finally, after the whole procedure all the stopovers were not related to rental or traffic.

\section{Conclusion}

The article contributes to a better understanding and use of data on the city bike travel. Research thus far has focused mainly on number and the spatial structure of such trips, looking into the various factors that affect the use of city bikes. In contrast, this study draws attention to possibility of employing data on the user stopovers for purposes of designing the bike infrastructure; it could also help to improve understanding of urban sociology, determine the patterns of urban mobility and identify the sites that are attractive for the city residents and tourists. This, in turn, may help municipal decision-makers to assess the potential of various public spaces and plan the urban development accordingly.

The proposed method has helped to use the new kind of data source to delimit attractive public spaces. The analysed example of Cracow showed that a large proportion of stopovers occurred in places widely recognized as tourist attractions, including the Vistula Boulevards and the Main Market Square. The data, however, would not have been useful without the proposed data filtering method, which discarded all the traffic-related stopovers from the sample. Using the raw data sample could have led to wrong conclusions, since for instance $82 \%$ of stopovers were connected with the bike-sharing stations. The proposed method allows to use the bike-sharing big datasets in the process of identifying the attractive public spaces. The proposed method is generally applicable to any city where the city bike data are available.

As the bike-sharing system in Cracow, Poland, case study shows, big data analytics is a technology with the potential to develop smart city services. These new data largely contribute to understanding the consumption of space within the urban tourist destinations and therefore enable to differentiate the overcrowded places from those with the potential to grow. This allows the decision-makers to imagine new ways of planning and managing towards a sustainable "smart" future.

\section{References}

[1] FALL, M., DABROWSKI, M. Jak rowery miejskie tworza „smart cities”. In: Biala Ksiega Mobilnosci 2015 [online]. Warsaw: Wydawnictwo Tor, 2015, p. 118-121. Available from: https://transport-publiczny.pl/BKM/BialaKsiegaMobilnosci2015.pdf

[2] LEE, P., HUNTER, W. C., CHUNG, N. Smart tourism city: developments and transformations. Sustainability [online]. 2020, 12(10), 3958. ISSN 2071-1050. Available from: https://doi.org/10.3390/su12103958

[3] BAKICI, T., ALMIRALL, E., WAREHAM, J. A smart city initiative: the case of Barcelona. Journal of the Knowledge Economy [online]. 2013, 4(2), p. 135-148. ISSN 1868-7865, eISSN 1868-7873. Available from: https://doi.org/10.1007/ s13132-012-0084-9

[4] BARDI, A., MANTECCHINI, L., GRASSO, D., PAGANELLI, F., MALANDRI, C. Flexible mobile hub for e-bike sharing and cruise tourism: a case study. Sustainability [online]. 2019, 11(19), 5462. ISSN 2071-1050. Available from: https://doi.org/10.3390/su11195462

[5] BUHALIS, D., BOES, K., INVERSINI, A. Smart tourism destinations: ecosystems for tourism destination. International Journal of Tourism Cities [online]. 2016, 2(2), p. 108-124 [accessed 2020-06-26]. ISSN 2056-5607. Available from: https://doi.org/10.1108/IJTC-12-2015-0032

[6] PUCHER, J., BUEHLER, R. Cycling for everyone: lessons from Europe. Transportation Research Record: Journal of the Transportation Research Board [online]. 2008, 2074(1), p. 58-65. ISSN 0361-1981, eISSN 2169-4052. Available from: https://doi.org/10.3141/2074-08

[7] KUZMYAK, J. R., DILL, J. Walking and bicycling in the United States: the who, what, where, and why. TR News [online]. 2012, 280, p. 4-15. ISSN 0738-6826. Available from: http://onlinepubs.trb.org/onlinepubs/trnews/trnews280www.pdf 
[8] PROULX, F. R., POZDNUKHOV, A. Bicycle traffic volume estimation using geographically weighted data fusion. Journal of Transport Geography. 2017, p. 1-14. ISSN 0966-6923.

[9] NAIR, R., MILLER-HOOKS, E., HAMPSHIRE, R. C., BUSIC, A. Large-scale vehicle sharing systems: analysis of Velib. International Journal of Sustainable Transportation [online]. 2013, 7(1), p. 85-106. Available from: https://doi.org/10. 1080/15568318.2012.660115

[10] FROEHLICH, J., NEUMANN J., OLIVER, N. Sensing and predicting the pulse of the city through shared bicycling. In: 21st International Joint Conference on Artificial Intelligence IJCAI-09: proceedings. Vol. 3. 2009. p. 1420-1426. Available from: https://doi.org/10.1.1.150.4370

[11] ZHAO, J., FAN, W., ZHAI, X. Identification of land-use characteristics using bicycle sharing data: A deep learning approach. Journal of Transport Geography [online]. 2020, 82, 102562. ISSN 0966-6923. Available from: 10.1016/j. jtrangeo.2019.102562.

[12] SHEN, L., STOPHER, P. R. Review of GPS travel survey and GPS data-processing methods. Transport Reviews [online]. 2014, 34(3), p. 316-334. ISSN 0144-1647, eISSN 1464-5327. Available from: https://doi.org/10.1080/01441647.2014.903530

[13] IMANI, A. F., ELURU, N., EL-GENEIDY, A., RABBAT, M., HAQ, U. How does land-use and urban form impact bicycle flows: evidence from the bicycle-1 sharing system (BIXI) in Montreal. Journal of Transport Geography [online]. 2014, 41, p. 306-314. ISSN 0966-6923. Available from: https://doi.org/10.1016/j.jtrangeo.2014.01.013

[14] FRADE, I., RIBEIRO, A. Bicycle sharing systems demand. Procedia - Social and Behavioral Sciences [online]. 2014, 111, p. 518-527. ISSN 1877-0428. Available from: https://doi.org/10.1016/j.sbspro.2014.01.085

[15] CANTELMO, G., KUCHARSKI, R., ANTONIOU, C. A low dimensional model for bike sharing demand forecasting. In: 6th International Conference on Models and Technologies for Intelligent Transportation Systems MT-ITS 2019: proceedings [online]. 2019. Available from: https://doi.org/10.1109/MTITS.2019.8883283

[16] ETIENNE, C., LATIFA, O. Model-based count series clustering for bike sharing system usage mining: a case study with the Velib' system of Paris. ACM Transactions on Intelligent Systems and Technology [online]. 2014, 5(3), p. 1-21. ISSN 2157-6904, eISSN 2157-6912. Available from: https://doi.org/10.1145/2560188

[17] NOUSSAN, M., CARIONI, G., SANVITO, F. D., Colombo, E. Urban mobility demand profiles: time series for cars and bike-sharing use as a resource for transport and energy modelling. Data [online]. 2019, 4(3), 108. eISSN $2306-5729$. Available from: https://doi.org/10.3390/data4030108

[18] BUCK, D., BUEHLER, R. Bike lanes and other determinants of capital bikeshare trips. Transp. In: Transportation Research Board 91st Annual Meeting: proceedings. 2012. p. 703-706.

[19] RIXEY, R. Station-level forecasting of bikesharing ridership. Transportation Research Record: Jourmal of the Transportation Research Board [online]. 2013, 2387(1), p. 46-55. ISSN 0361-1981, eISSN 2169-4052. Available from: https://doi.org/10.3141/2387-06

[20] WANG, X., LINDSEY; G., SCHONER; J. E., HARRISON, A. Modelling bike share station activity: the effects of nearby businesses and jobs on trips to and from stations. In: TRB's 92nd Annual Meeting and Publication in the Transportation Research Record: proceedings. 2012.

[21] TRAN, T. D., OVTRACHT, N., D'ARCIER, B. F. Modeling bike sharing system using built environment factors. Procedia CIRP [online]. 2015, 30, p. 293-298. ISSN 2212-8271. Available from: https://doi.org/10.1016/j.procir.2015.02.156

[22] SALON, D., CONWAY, M. W., WANG, K., ROTH, N. Heterogeneity in the relationship between biking and the built environment. Journal of Transport and Land Use [online]. 2019, 12(1), p. 99-126. ISSN 1938-7849. Available from: https://doi.org/10.5198/jtlu.2019.1350

[23] EREN, E., UZ, V. E. A review on bike-sharing: the factors affecting bike-sharing demand. Sustainable Cities and Society [online]. 2020, 54, 101882. ISSN 2210-6707. Available from: https://doi.org/10.1016/j.scs.2019.101882

[24] ZHANG, Y., THOMAS, T., BRUSSEL, M., VAN MAARSEVEEN, M. Exploring the impact of built environment factors on the use of public bikes at bike stations: case study in Zhongshan, China. Journal of Transport Geography [online]. 2017, 58, p. 59-70. ISSN 0966-6923. Available from: https://doi.org/10.1016/j.jtrangeo.2016.11.014

[25] CAULFIELD, B., O'MAHONY, M., BRAZIL, W., WELDON, P. Examining usage patterns of a bike-sharing scheme in a medium sized city. Transportation Research Part A: Policy and Practice [online]. 2017, 100, p. 152-161. ISSN 0965-8564. Available from: https://doi.org/10.1016/j.tra.2017.04.023

[26] WANG, J., LINDSEY, G. Neighborhood socio-demographic characteristics and bike share member patterns of use. Journal of Transport Geography [online]. 2019, 79, 102475. ISSN 0966-6923. Available from: https://doi.org/10.1016/j. jtrangeo.2019.102475

[27] YAN, Q., GAO, K., SUN, L., SHAO, M. Spatio-temporal usage patterns of dockless bike-sharing service linking to a metro station: a case study in Shanghai, China. Sustainability [online]. 2020, 12(3), 851. eISSN 2071-1050. Available from: https://doi.org/10.3390/su12030851

[28] WANG, Z., CHENG, L., LI, Y., LI, Z. Spatiotemporal characteristics of bike-sharing usage around rail transit stations: evidence from Beijing, China. Sustainability [online]. 2020, 12(4), 1299. eISSN 2071-1050. Available from: https://doi.org/10.3390/su12041299 
[29] KOERBITZ, W., ONDER, I., HUBMANN-HAIDVOGEL, A. C. Identifying tourist dispersion in Austria by digital footprints. In: Information and Communication Technologies in Tourism 2013: proceedings [online]. Berlin Heidelberg: Springer, 2013. ISBN 978-3-642-36308-5, eISBN 978-3-642-36309-2, p. 495-506. Available from: https://doi.org/10.1007/978-3-64236309-2_42

[30] MIAH, S. J., VU, H. Q., GAMMACK, J., McGRATH, M. A big data analytics method for tourist behaviour analysis. Information and Management [online]. 2017, 54(6), p. 771-785. ISSN 0378-7206. Available from: https://doi. org/10.1016/j.im.2016.11.011

[31] HASNAT, M. M., HASAN, S. Identifying tourists and analyzing spatial patterns of their destinations from location-based social media data. Transportation Research Part C: Emerging Technologies [online]. 2018, 96, p. 38-54. ISSN 0968090X. Available from: https://doi.org/10.1016/j.trc.2018.09.006

[32] BRINKMANN, J. Active balancing of bike sharing systems [online]. Berlin Heidelberg: Springer, 2020. ISBN 978-3-03035011-6, eISBN 978-3-030-35012-3. Available from: https://doi.org/10.1007/978-3-030-35012-3

[33] NAUMOV, V., BANET, K. Estimating parameters of demand for trips by public bicycle system using GPS data. In: Smart and Green Solutions for Transport Systems TSTP 2019: proceedings [online]. Advances in Intelligent Systems and Computing. Vol. 1091. Cham: Springer, 2020. ISBN 978-3-030-35542-5, eISBN 978-3-030-35543-2. Available from: https:// doi.org/10.1007/978-3-030-35543-2_17

[34] Cracow-Balice. Historical measurement data of the Polish Institute of Meteorology and Water Management / CracowBalice. Historyczne dane pomiarowe IMGW (in Polish) [online] [accessed 2020-04-19]. Available from: https:// meteomodel.pl/dane/historyczne-dane-pomiarowe/?data=2017-06-07\&rodzaj=st\&imgwid=350190566\&dni=60\&ord=d esc 